\title{
Research Trends on Young Children's Happiness: Focusing on Young Children, Parents, and Teachers
}

\author{
Youngsook Kim, Sunhee Min \\ Department of Early Childhood Education, Joongbu University, Goyang, Korea \\ 영·유아 행복 연구동향 분석: 영·유아, 부모, 교사를 중심으로 \\ 김용숙, 민선희 \\ 중부대학교 유아교육과
}

Objective: The purpose of this study was to analyze the research trends in happiness of young children and to suggest the direction of future happiness program development and happinessrelated research.

Methods: The results of analysis of 244 articles and academic papers for young children, parents, and teachers from 2008 to 2016 are summarized as follows.

Results: First, in time analysis, related research was first conducted in 2008; it surged in 2013, and peaked in 2015. Second, there were many practical studies in this research area, but relatively few basic researches. Basic research was conducted in the order of recognition and actual research, trend research, and theoretical research. Additionally, practical research was conducted in the order of variable research, program development and effect research, and scale development research. Third, in the trends of research methods, quantitative research was the highest, followed by qualitative research, literature reviews, and multiple researches. Moreover, the number of qualitative studies is increasing. Fourth, in trends of research subjects, most were with young children, followed by teachers, parents, and literature. Most of the happiness researches for young children and parents were conducted with children. In addition, most of the happiness researches for teachers were conducted with in-service teachers.

Conclusion: The results of this study will help to understand the flow of happiness research for young children, parents, and teachers, and will provide a basis for establishing the direction of happiness-related research such as the development of happiness programs and measurement.

Keywords: young children's happiness, parental happiness, teachers' happiness, trends in research$$
\text { 서론 }
$$

인간이 삶을 살아가는데 있어서 인생의 궁극적인 목표는 '행 복한 삶'을 살아가는 것이다. 따라서 대부분의 사람들은 '행 복한 삶'을 살아가기 위해 노력하고 있다. 하지만 대한민국에 서 “당신은 지금 행복하십니까?”라는 물음에 자신 있게 “행복

Corresponding Author: Sunhee Min, Department of Early Childhood Education, Joongbu University, Geumsan, Korea

E-mail: saysv2@hanmail.net
\end{abstract}

합니다.”라고 대답할 수 있는 사람은 많지 않을 것이다. UN은 '세계행복지수보고서'를 통해 세계 여러 나라의 행복수치를 발표하고 있다. 이 보고서에 따르면 한국의 행복지수는 2014 년 47위를 기록하였으며, 2017년 현재 155개국 중 56위를 기 록하여 3년 만에 행복순위가 9단계나 하락한 것으로 나타났 다(Helliwer, Layard, \& Sachs, 2017). 그렇다면 아동의 행복지수

(C)The Korean Association of Child Studies

This is an Open Access article distributed under the terms of the Creative Commons Attribution Non-Commercial License (http:// creativecommons.org/licenses/by-nc/4.0) which permits unrestricted noncommercial use, distribution, and reproduction in any medium, provided the original work is properly cited. 
는 어떠할까? 우리나라 아동의 행복지수를 조사한 연세대 사 회발전연구소의 조사에 따르면 우리나라 아동의 행복지수는 $\mathrm{OECD}$ 국가들 중 최하위를 기록하였다(H. Hwang, Nam, Seo, $\& \mathrm{Kim}, 2016)$. 이러한 결과는 우리나라의 성인 뿐 아니라 아 동도 행복한 삶을 살지 못하고 있음을 직 - 간접적으로 보여주 는 것이라 할 수 있다.

영·유아기 행복의 중요성에 대해 자세히 살펴보면, Yang (2008)은 어린시기의 행복감이 성인이 된 후의 개개인의 행복 감과 삶의 질에도 영향을 준다고 하며 영·유아기 행복교육을 강조하였다. 그리고 E. J. Lee (2010)는 행복한 영 · 유아는 자신 감이 넘치고, 열정적이어서 건강한 사회적 관계를 형성하며 행복한 삶을 살아갈 수 있다고 이야기함으로써 영·유아기 행 복경험을 강조하였다. 또한 영·유아기 행복은 행복한 성인의 초석을 제공할 뿐만 아니라 미래 사회를 이끌어나갈 행복한 인재 양성을 통해 행복한 사회를 만드는데 기초를 제공할 것 이다. 행복한 영·유아가 더 능동적으로 학습하고, 전인적 성 장과 발달을 이룰 수 있으며, 더 행복한 학습자가 될 수 있음이 알려지며 근래에 영·유아의 행복과 관련된 연구가 많은 관심 을 받기 시작하였다. 이러한 사회적 분위기는 영·유아권리보 장, 국제적 인권이나 시민적 자유에 관계되는 것, 양육과 보호 받을 권리, 다양성 인정 등을 반영한 행복 교육에 대한 관심의 증가로 이어지게 되었다(Choe, 2015).

세계적으로 영·유아 행복과 관련하여 이루어진 연구들을 살펴보면, UNICEF는 아동웰빙지표를 구성하여 경제 선진국 으로 분류되어지고 있는 나라들을 대상으로 아동복지실태를 분석하여 세계의 아동복지증진방향을 논의함으로써 행복과 관련된 연구를 진행하였다. 다음으로 $\mathrm{OECD}$ 는 물질적 웰빙, 교육적 웰빙, 건강과 안전, 주거와 환경, 위험행동, 학교생활의 질 등 6개 영역으로 나누어 아동의 웰빙지표를 구성하였다. 또 한 유럽의 아동 웰빙 지수 연구팀에서는 UN 아동권리협약을 비준한 이후 아동의 권리에 관심을 갖고 아동의 웰빙과 행복 감, 개발과제, 미래의 문제까지 포괄해 아동의 행복에 대해 알 아보고자 연구를 진행하였다(Do, Bae, \& Kim, 2014).

이와 같이 영·유아의 행복 연구가 세계적으로 관심을 받기 시작하면서 영·유아 행복에 영향력을 미칠 수 있는 인간관계 즉, 부모와 교사의 행복 또한 그 중요성이 부각되었다. 영 - 유아 는 부모와 최초의 인간관계를 맺으며 그들의 사회적 행동을 모 방하고, 행복감을 물려받게 된다. D. R. Kim과 Kim (2008)은 유 아의 행복감과 부모의 행복감간의 관계를 규명하였는데 연구 를 통해 둘 사이가 서로 정적 상관관계를 가지며 부모 행복이 유아 행복에 중요한 영향을 미침을 밝혔다. 또한 최근 사회구조
의 변화(가족구조 변화, 맞벌이 부부 증가 등)로 인해 영·유아 는 가정에서 보다 유아교육기관에서 머무는 시간이 많아졌다. 그럼으로써 부모 못지않게 교사 또한 영·유아의 행복감 발달 에 직접적인 영향을 미치게 되었다. Kwark (2011)는 유아교사가 행복에 관심을 가지며 행복감을 증진시키려 노력한다면 교사유아 상호작용에 긍정적 영향을 미칠 것이고, 이는 궁극적으로 영 · 유아의 행복감을 증진시킬 것이라 이야기하며 교사 행복과 유아 행복의 관계를 강조하였다. 따라서 영·유아의 행복에 대 해 파악하기 위해서는 영·유아뿐만 아니라 부모, 교사의 행복 감간의 관계에 대한 규명이 이루어져야 할 것이다.

현재까지 이루어진 영·유아, 부모, 교사 행복 연구들을 자 세히 살펴보면, 영·유아 행복이론에 관한 연구(Ryu, 2013), 영 · 유아 행복에 대한 인식연구(Y. W. Kang, 2009; S. S. Kim, 2013), 교사 행복에 대한 인식연구(M. J. Kim, \& B. M. Kim, 2012; YI, 2015), 부모 행복에 대한 인식연구(Choi \& Chung, 2015) 등이 있다. 다음으로 영·유아 행복교육과 관련된 연구 의 동향 분석(H. K. Kang, 2014; Song, 2014; K. Lee, Yoon, \& Byeon, 2016), 영 · 유아의 행복증진 프로그램 개발 연구(S. H. Kim, \& Kang, 2008; Y. Kim, 2011; J. Kim \& Bang, 2014; J. Park, 2015; J. H. Shin, 2016), 영 · 유아와 교사의 행복척도 개발 및 타당화 연구(M. W. Nam \& Oh, 2016; E. J. Lee, 2010; Lim, $\mathrm{Kim}, \&$ Jeon, 2014) 등이 있다. 마지막으로 영·유아 행복 변 인연구(S. B. Kim, 2012; Oh, Kim, \& Lee, 2015; Na \& Hwang, 2014), 부모 행복 변인연구(H. J. Nam, 2015; Ha, 2016; Y. S. Lee, 2015; H. O. Lee, 2014), 교사 행복 변인연구(S. H. Park \& E. J. Park, 2014; S. B. Lee, 2015; Won, 2015; H. I. Hwang \& Kim, 2016) 등이 있다. 지금까지 이루어진 행복 연구들은 행복에 영 향을 미치는 변인에 관한 연구가 가장 많이 이루어졌다.

영 - 유아에게 있어서 행복이란 가족, 또래, 교사 등의 주변 인간관계와 놀이, 다양한 활동 등의 일상적 생활경험을 통해 스스로의 행동에 만족감을 느끼는 상태로써, 지극히 주관적인 것이라고 정의할 수 있다(Gwon \& Sung, 2010). 이러한 영·유 아 행복의 정의를 통해 영 · 유아의 행복이 그들을 둘러싸고 있 는 인적, 물리적환경과의 상호작용이 그들에게 긍정적인 느낌 을 줄 수 있느냐 없느냐에 따라 결정된다는 것을 알 수 있다. 이렇듯 영·유아의 행복은 지극히 주관적인 경험의 느낌이다. 때문에 영 · 유아 행복 관련 연구는 일상적 생활에서의 행복 경 험을 실질적으로 볼 수 있는 질적연구를 통해 이루어져야 할 것이다. 하지만 위에서 살펴본 것과 같이 영·유아 행복에 대 한 질적연구가 미흡한 상태이다.

또한 현재까지 이루어진 행복 연구는 유아 대상 연구가 대부 
분으로 영아 대상 연구는 극히 일부분에 불과하다. 이러한 현상 의 원인에 대해 G. Y. Kim (2017)은 영아의 언어 발달수준 및 인 지 발달수준이 연구에 적합하지 않다는 연구자들의 잘못된 인 식과 영아용 행복 연구 도구선정의 어려움을 이야기하였다.

이와 같이 영 - 유아 행복과 관련된 연구들은 아직 많은 문 제점을 가지고 있다. 이러한 문제점들을 구체적으로 파악하여 앞으로 이루어질 영·유아 행복 연구의 방향을 제시해 줄 수 있어야 할 것이다. 이를 위해서는 영 · 유아와 영 · 유아 행복에 가장 많은 영향을 미치는 부모, 교사의 행복에 관한 연구를 포 괄적으로 분석해 볼 필요가 있으나, 현재까지 이루어진 영 · 유 아 행복 관련연구의 동향 분석은 유아를 대상으로 한 행복 연 구만을 분석하였거나 부모 혹은 교사로 국한되어 이루어졌다.

따라서 이 연구의 목적은 현재까지 이루어진 영·유아, 부 모, 교사 행복에 관한 연구동향을 분석함으로써, 행복 연구의 흐름과 문제점들을 파악하여 추후 이루어질 영 · 유아 행복 연 구의 방향을 제시하고자 하는데 있다. 이러한 연구의 목적에 기초하여 연구문제를 다음과 같이 설정하였다.

\section{연구문제 1}

영·유아 행복 연구의 연구시기에 따른 연구동향은 어떠한가?

\section{연구문제 2}

영·유아 행복 연구의 연구주제에 따른 연구동향은 어떠한가?

\section{2-1 기초연구에 따른 연구동향은 어떠한가?}

\section{2-2 실천연구에 따른 연구동향은 어떠한가?}

\section{연구문제 3}

영· 유아 행복 연구의 연구방법에 따른 연구동향은 어떠한가?

\section{연구문제 4}

영·유아 행복 연구의 연구대상에 따른 연구동향은 어떠한가?

\section{연구방법}

\section{분석대상}

영 - 유아 행복의 동향과 내용을 분석하기 위해 학위 및 학술 논문을 검색해본 결과 2008년에 최초로 연구가 이루어진 것
으로 나타났다. 따라서 2008년에서 2016년까지 영·유아와 교 사, 부모를 대상으로 한 영·유아 행복 학위 및 학술논문을 분석 대상으로 선정하였다. 분석대상의 선정과정은 RISS (Research Information Sharing Service)와 KISS (Koreanstudies Information Service System), 국회도서관에서 키워드를 입력하는 방식으로 총 3 차에 걸쳐 이루어졌다.

1 차에서는 ‘영·유아 행복', ‘영·유아 행복-부모', ‘영·유아 행복-교사'를 차례로 검색하였으며, 검색되어진 논문들 중 제 목에 ‘영·유아 행복', '부모', '교사'가 직접적으로 포함되어진 109 편의 학위논문과 168 편의 학술논문 총 277 편의 논문을 1 차 분석대상으로 선정하였다. 2 차에서는 논문제목, 핵심어, 연 구문제, 본문내용, 연구결과를 중심으로 살펴보았다. 학위논 문과 학술논문이 겹치는 논문은 학술논문에서 제외시켰으며, 논문 내용이 영 · 유아 행복과 연관이 없거나 본문 확인이 어려 운 논문, 학술대회발표용 논문과 포스터 발표, 기초강연 논문 등을 제외하고, 108 편의 학위논문과 142 편의 학술논문으로 250 편의 논문이 선정되었다. 마지막 3 차에서는 250 편의 논문 을 다운로드하여 본문내용을 살펴보고, 영·유아와 부모, 교사 의 행복과 직접적으로 관련되지 않은 논문 5편을 제외한 109 편의 학위논문과 136 편의 학술논문 (총 245 편)을 최종 분석대 상으로 선정하였다.

\section{분석기준 및 방법}

국내에서 발표된 영·유아 행복 학위·학술논문 중에서 영·유 아교육과 관련된 논문을 중심으로 분석·종합·해석하는 문헌 연구방법을 사용하였다. 특히 영·유아와 관련된 행복 논문의 연구동향을 분석하기 위해 영·유아 행복과 부모, 교사가 중심 주제(제목)로 나타나는 논문 245편을 분석대상으로 하였다. 선 정된 논문을 연구시기, 연구주제, 연구방법, 연구대상으로 구분 하여 살펴보았으며, 이를 구체적으로 제시하면 다음과 같다.

\section{연구시기에 따른 연구동향}

본 연구는 2016년 12월까지 발행된 석 · 박사 학위논문과 학술 논문을 대상으로 각각 범주별 연구논문을 2008년에서 2016년 까지 1 년 단위로 구분하여 시기별로 살펴보았다.

$$
\text { 연구주제에 따른 연구동향 }
$$

연구주제 분석기준은 선행연구 (H. K. Kang, 2014; Y. S. Kim 
Table 1

Classification Criteria by Research Theme

Contents

Detailed category

Basic research

Happiness theory

Awareness and reality

Analysis of trends

Action-based research

Program development and effectiveness

Scale development

Variables

Demographic variables

Cognitive variables

Emotional variables

Social variables

Moral variables
- Theoretical studies related to young children's happiness: Discourse of desire, brain research, possibility, relationship orientation, emotion

- A study on perception and actual condition of happiness of young children

- A study analyzing the trends in research on the happiness of young children

- Development of program to promote happiness and verification of its effect

- Young children: Happiness education, picture book (sharing education, integration activity, read, audit training, ecological picture book, active activity, role play, positive psychological fairy tales), Nuri course, green food life, forest program (cooperative play, free play), personality education, nature friendship (sensory play), traditional play, traditional stories, music activity (outdoor music activity, instrument, dalcroze eurhythmics music program), cooperative art activities

- Parents: Parent education based on e-learning, forest program

- Teachers: Forest program, cooperative health program, happy flourish, happiness promotion, happy training, thanks diary

- Development of a scale to measure happiness

- Young children: Gender, age, temperament, attachment, birth order

- Parents: academic background, economic strength, occupation, personality traits, attachment, age

- Teachers: Teaching profession aptitude, academic background, age, working type, career, personality strength, endowment

- Young children: Creativity

- Parents: Ability, coaching

- Teachers: Immersion (teaching, organization), creativity, self-development, educational belief (enjoyment belief), empowerment, professionalism recognition, self-determination

- Young children: Vessel, self-esteem, audit propensity, ego resilience, emotional intelligence

- Parents: Resilience, young children's happiness, job satisfaction, parenting efficacy, parenting stress, parent satisfaction, stroke type

- Teachers: Teacher efficacy, positive sentiment, self-esteem, ego resilience, job satisfaction, tenacity, emotional intelligence, dedication, emotion expression, psychological exhaustion, emotional labor, audit propensity

- Young children: Solving the great human problem, kindergarten adaptation, leadership, peer competence, social support

- Parents: Marital relationship, parenting attitude, participation in play, child relationship, empathy ability, participation in parenting

- Teachers: Empathy ability, adaptive flexibility, turnover intention, perform a role, interpersonal competence, self-leadership, interaction, social support, stress (job stress, interpersonal stress, stress coping), humor

- Young children: Problem behavior, moral judgment

- Teachers: Young children problem behavior 
\& Shin, 2016; J. H. Shin \& Choi, 2014; K. M. Lee, 2009; K. Lee, Yoon, \& Byeon, 2016)의 연구주제 분석기준을 토대로 수정 · 보 완하여 사용하였다. 선정한 연구주제별 분류기준 및 세부분석 기준을 유아교육 전문가 2 인과의 협의를 통해 최종선정하였 다. 연구주제에 따른 연구동향은 기초연구(영·유아 행복 이 론에 관한 연구, 인식 및 실태, 동향분석)와 실천 연구(프로그 램 개발 및 효과, 척도개발, 변인 관련 연구)로 최종 선정하였 으며, 한편의 논문에 두 가지 이상의 연구주제를 포함하는 경 우 해당 연구주제를 확인하여 복수 처리 후 분석하였다. 연구 주제의 자세한 세부기준은 Table 1 과 같다.

\section{연구방법에 따른 연구동향}

연구유형 분석기준은 선행연구(M. S. Song, 2014; K. Lee, Yoon, \& Byeon, 2016)의 연구유형 분석기준을 토대로 수정 - 보완하 여 사용하였다. 선정한 연구유형 분석기준은 유아교육 전문가 2 인과의 협의를 통해 최종 선정하였다. 연구유형은 양적연구, 질적연구, 문헌연구, 다중연구의 4 가지 범주로 분류하였으며, 한편의 논문에 두 가지 이상의 연구유형을 포함하는 경우 해 당 연구유형을 확인하여 다중연구로 처리하여 분석하였다. 연 구방법의 자세한 세부기준은 Table 2와 같다.

Table 2

Classification Criteria by Research Method

\begin{tabular}{ll}
\hline \multicolumn{1}{c}{ Contents } & \multicolumn{1}{c}{ The details } \\
$\begin{array}{l}\text { Quantitative research } \\
\begin{array}{l}\text { Experimental research } \\
\text { Survey research }\end{array}\end{array}$ & $\begin{array}{l}\text { Theory-based hypothesis testing } \\
\text { How to collect data through } \\
\text { questionnaires }\end{array}$ \\
$\begin{array}{ll}\text { Correlation research } \\
\text { How to analyze or predict relationships } \\
\text { between variables }\end{array}$ \\
$\begin{array}{ll}\text { Qualitative research } \\
\begin{array}{l}\text { Ethnographic research } \\
\text { Narrative research }\end{array}\end{array}$ & $\begin{array}{l}\text { Research methods that describe culture } \\
\text { scenes and storylines } \\
\text { observation }\end{array}$ \\
$\begin{array}{l}\text { Literature research } \\
\text { Multiple researches }\end{array}$ & $\begin{array}{l}\text { Research methods through interview } \\
\text { and observation }\end{array}$ \\
\hline
\end{tabular}

\section{연구대상에 따른 연구동향}

연구대상 분석기준은 선행연구(M. S. Song, 2014; K. Lee, Yoon, \& Byeon, 2016)의 연구대상 분석기준을 토대로 수정 - 보완하
Table 3

Classification Criteria by Research Subject

\begin{tabular}{|c|c|}
\hline Contents & The details \\
\hline \multicolumn{2}{|l|}{ Young children } \\
\hline Age & One to five year olds \\
\hline \multicolumn{2}{|l|}{ Parents } \\
\hline Mother & $\begin{array}{l}\text { Adult women who have or have raised } \\
\text { young children }\end{array}$ \\
\hline Father & An adult man raising young children \\
\hline \multicolumn{2}{|l|}{ Teachers } \\
\hline Preliminary teacher & A teacher in a teacher training institution \\
\hline Incumbent teacher & $\begin{array}{l}\text { A teacher at an early childhood education } \\
\text { institution }\end{array}$ \\
\hline Literature & $\begin{array}{l}\text { Papers, books and picture books related to } \\
\text { young children and their happiness }\end{array}$ \\
\hline
\end{tabular}

여 사용하였다. 선정한 연구대상의 분류기준은 유아교육 전문 가 2 인과의 협의를 통해 최종 선정하였다. 최종 선정된 연구대 상은 영·유아(단일연령), 부모(아버지, 어머니), 교사(예비교 사, 현직교사) 문헌의 4 가지 범주로 분류하였으며, 한편의 논 문에 두 가지 이상의 연구대상을 포함하는 경우 해당 연구대 상을 확인하여 복수 처리 후 분석하였다. 연구대상의 자세한 세부기준은 Table 3과 같다.

\section{연구절차}

영 · 유아 행복 연구논문의 발행시기, 연구주제, 연구방법 및 연구대상을 알아보기 위해 2017년 1월 9일부터 1월 31일에 걸 쳐 예비조사를 실시하였다. 연구의 객관성 확보를 위해 유아 교육전문가 2인과 함께 예비분석을 실시하였다. 대상논문은 이 논문의 연구대상논문 중 무선으로 20 편을 선정하여 분석 범주표를 기준으로 분석하였으며, 이때 사용한 분석자간 일치 도는 산출공식인 '(일치된 분석항목 수/전체항목수) $\times 100$ ’으 로 $85 \%$ 의 일치도를 산출하였다. 분석한 결과를 토대로 불일 치하는 부분에 대한 의견을 나누고 선행연구와 서적을 참고로 자료 분석 기준을 수정하였으며, 다시 10 편을 선정하여 각자 분석한 결과, 일치도는 $94 \%$ 로 나타났다. 예비조사를 기초로 수정·보완한 분석 범주표를 기준으로 2017년 2월 1일에서 3 월 10 일까지 6주에 걸쳐 본 조사를 실시하였다.

\section{자료분석}

연구대상 논문은 자료 분석 기준 및 방법에 따라 분류한 후 
Table 4

Research Trends According to Year of Publication

\begin{tabular}{|c|c|c|c|c|c|c|c|c|c|c|}
\hline Division Year & 2008 & 2009 & 2010 & 2011 & 2012 & 2013 & 2014 & 2015 & 2016 & Sum \\
\hline Master & 1 & 2 & 2 & 3 & 2 & 11 & 14 & 25 & 26 & $86(35.2)$ \\
\hline Doctor & & 1 & 2 & 1 & 1 & 1 & 2 & 8 & 7 & $23(9.3)$ \\
\hline Journal & 1 & 2 & 2 & 2 & 11 & 18 & 29 & 46 & 25 & $136(55.7)$ \\
\hline Total & $2(0.8)$ & $5(2.0)$ & $6(2.4)$ & $6(2.4)$ & $14(5.7)$ & $30(12.3)$ & 45 (18.4) & $79(32.4)$ & $58(23.6)$ & $245(100.0)$ \\
\hline
\end{tabular}

Note. $N=245$. Numbers in brackets represent percentages.

SPSS 21.0 (IBM Co., Armonk, NY)을 이용하여 연구문제에 따 라 빈도와 백분율을 산출하였다.

\section{연구결과}

\section{발행연도에 따른 연구동향}

발행연도에 따른 연구동향을 분석한 결과는 Table 4와 같다.

Table 4와 같이 발행연도에 따른 연구동향을 살펴보면, 2008 년도에는 2 편(0.8\%)의 연구가 이루어졌으며, 2009년도에 5편(2.0\%), 2010년도와 2011년도에 각각 6편(2.4\%), 2012년 도에 14편(5.7\%), 2013년도에 30편(12.3\%), 2014년도에 45편 (18.4\%), 2015년도에 79편(32.4\%), 2016년도에 58편(23.6\%) 으로 나타났다. 또한 2008년도부터 2016년까지 발행된 석사 학위논문은 총 86편(35.2\%)이며, 박사학위논문은 총 23 편 (9.3\%), 학술논문은 총 136편(55.7\%)으로 나타났다. 이를 통해 영 · 유아교육 관련 행복 연구가 2008년에 처음으로 나타났으
며, 2012년도에 연구의 양이 점차 증가해 2015년까지 가장 많 은 연구가 이루어졌고, 2016년에는 연구가 다소 감소한 것을 알 수 있다. 또한 논문의 종류별로 살펴보았을 때 학술논문의 연구가 가장 많이 이루어졌고, 그 다음 석사논문, 박사논문 순 으로 이루어졌음을 알 수 있다.

\section{연구주제에 따른 연구동향}

발행연도에 따른 연구동향을 분석한 결과는 Table 5와 같다.

Table 5와 같이 연구주제에 따른 연구주제별로 기초연구와 실천연구로 살펴보면, 기초연구 36편(13.6\%)중 인식·실태 연 구가 22편(8.3\%)으로 가장 많이 이루어졌으며, 그 다음 동향 분석 9편(3.4\%), 이론 5편(1.9\%) 순으로 나타났다. 실천연구 228 편(86.4\%) 중 변인 연구가 165 편(62.5\%)으로 가장 많이 이 루어졌으며, 그 다음 프로그램 개발 및 효과 57편(21.5\%), 척 도개발 6 편 $(2.3 \%)$ 순으로 나타났다. 이를 통해 기초연구보다 실천연구가 많이 이루어졌으며, 이론에 대한 연구와 척도개발 에 대한 연구의 수가 부족함을 알 수 있다.

Table 5

Research Trends by Subject

\begin{tabular}{|c|c|c|c|c|c|c|c|c|c|c|}
\hline Year & 2008 & 2009 & 2010 & 2011 & 2012 & 2013 & 2014 & 2015 & 2016 & Sum \\
\hline \multicolumn{11}{|l|}{ Basic research } \\
\hline Theory & & 1 & & & & 2 & & 1 & 1 & $5(1.9)$ \\
\hline Trend analysis & & & & & 1 & 2 & 3 & 1 & 2 & $9(3.4)$ \\
\hline Cognition & & 1 & 1 & & 3 & 2 & 5 & 7 & 3 & $22(8.3)$ \\
\hline Sum & & 2 & 1 & & 4 & 6 & 8 & 9 & 6 & $36(13.6)$ \\
\hline \multicolumn{11}{|l|}{ Practical research } \\
\hline Program development and effectiveness & 1 & 1 & & 2 & 2 & 8 & 8 & 23 & 12 & $57(21.5)$ \\
\hline Scale development & & & 1 & & & & 1 & 2 & 2 & $6(2.3)$ \\
\hline Variable & 1 & 2 & 5 & 4 & 10 & 19 & 31 & 51 & 42 & $165(62.5)$ \\
\hline Sum & 2 & 3 & 6 & 6 & 12 & 27 & 40 & 76 & 56 & $228(86.4)$ \\
\hline Total & $2(0.7)$ & $5(1.9)$ & $7(2.7)$ & $6(2.3)$ & $16(6.0)$ & $33(12.5$ & $48(18.2)$ & $85(32.2)$ & $62(23.5)$ & $264(100.0)$ \\
\hline
\end{tabular}

Note. Duplicate response was allowed. 
Table 6

Research Trends in Basic Research Among Research Subjects

\begin{tabular}{|c|c|c|c|c|c|c|c|c|c|c|}
\hline Division $\quad$ Year & 2008 & 2009 & 2010 & 2011 & 2012 & 2013 & 2014 & 2015 & 2016 & Sum \\
\hline \multicolumn{11}{|l|}{ Theory } \\
\hline Discourse of desire $\mathrm{a}^{\mathrm{a}}$ & & & & & & 1 & & & & $1(2.6)$ \\
\hline Brain research ${ }^{\mathrm{a}}$ & & & & & & 1 & & & & $1(2.6)$ \\
\hline Possibility $^{\mathrm{a}}$ & & 1 & & & & & & & & $1(2.6)$ \\
\hline Relationship orientation ${ }^{a}$ & & & & & & & & 1 & & $1(2.6)$ \\
\hline Emotion $^{\mathrm{a}}$ & & & & & & & & & 1 & $1(2.6)$ \\
\hline Sum & & 1 & & & & 2 & & 1 & 1 & $5(13.1)$ \\
\hline \multicolumn{11}{|l|}{ Trend analysis } \\
\hline Paper $^{\mathrm{a}}$ & & & & & & & 2 & & 2 & $4(10.5)$ \\
\hline Literature $^{\mathrm{a}}$ & & & & & 1 & 2 & & & & $3(7.9)$ \\
\hline Program $^{a}$ & & & & & & & & 1 & & $1(2.6)$ \\
\hline Paper $^{\mathrm{b}}$ & & & & & & & 1 & & & $1(2.6)$ \\
\hline Paper $^{\mathrm{c}}$ & & & & & & & 2 & & & $2(5.3)$ \\
\hline Sum & & & & & 1 & 2 & 5 & 1 & 2 & $11(28.9)$ \\
\hline Cognition $^{a}$ & 1 & & 1 & & 1 & 2 & 3 & 5 & 2 & $15(39.5)$ \\
\hline Cognition $^{\mathrm{b}}$ & & & & & 2 & & 2 & 2 & 1 & $7(18.4)$ \\
\hline Sum & 1 & & 1 & & 3 & 2 & 5 & 7 & 3 & $22(57.9)$ \\
\hline Total & $1(2.6)$ & $1(2.6)$ & $1(2.6)$ & & $4(10.5)$ & $6(15.8)$ & $10(26.3)$ & $9(23.7)$ & $6(15.8)$ & $38(100.0)$ \\
\hline
\end{tabular}

Note. $N=38 . \mathrm{a}=$ young children; $\mathrm{b}=$ parents; $\mathrm{c}=$ teachers. Numbers in brackets represent percentages.

연구주제를 기초연구(이론, 인식 · 실태, 동향분석)와 실천 연구(프로그램 및 효과, 척도개발, 변인)로 분류하여 연구대상 (유아, 부모, 교사)에 따라 살펴보면 다음과 같다.

\section{기초연구}

연구주제 중 기초연구(이론, 인식·실태, 동향분석)에 대한 연 구동향을 살펴보면 Table 6과 같다.

Table 6과 같이 연구주제 중 기초연구를 세부항목별로 살 펴보면, 인식 · 실태에 대한 연구가 22편(57.9\%)으로 가장 많 이 이루어졌으며, 그 다음 동향연구 11 편(28.9\%), 이론연구 5 편(13.1\%) 순으로 나타났다. 이를 자세히 살펴보면, 인식·실 태연구는 총 22편(57.9\%)으로, 그 중 유아 행복의 인식 · 실태 연구는 15편(39.5\%)으로 나타났으며, 교사행복의 인식 · 실태 연구는 총 7편(18.4\%)으로 나타났다. 이를 통해 영 · 유아 행복 에 대한 인식 - 실태 연구가 많이 이루어졌음을 알 수 있다. 다 음으로 동향연구는 총 11 편(28.9\%), 유아 행복은 논문 동향이 4편(36.4\%), 문학동향 3편(27.3\%), 프로그램동향 1편(9.1\%) 순으로 나타났다. 부모행복은 논문동향 1 편(9.1\%)으로 나타 났으며, 교사행복은 논문동향 2편(18.2\%)으로 나타났다. 이
를 통해 유아 행복에 대한 동향연구가 가장 많이 이루어졌음 을 알 수 있다. 마지막으로 이론연구는 총 5편(13.1\%)으로, 욕 망담론, 뇌 연구, 가능성, 관계지향, 강점에 대한 연구가 각각 1 편(20.0\%)씩 연구된 것으로 나타났다. 이러한 결과를 통해 영 · 유아 행복에 대한 인식·실태 연구가 많이 이루어졌음을 알 수 있다.

\section{실천연구}

연구주제의 실천연구 중 프로그램 개발 및 효과, 척도개발의 연구동향을 살펴보면 Table 7과 같다.

Table 7과 같이 연구주제 중 프로그램 개발 및 효과를 연구 대상에 따라 살펴본 결과, 영 - 유아를 대상으로 개발된 프로그 램 중 그림책이 12 편(19.0\%)으로 가장 많이 나타났으며, 다음 으로 자연친화 교육활동 9편(14.2\%), 솦 프로그램 6편(9.5\%), 행복교육과 전통놀이가 각각 4편(6.3\%), 음악활동 3편(4.7\%), 누리과정과 바깥놀이가 각각 2편(3.1\%), 녹색식생활, 인성교 육, 전래동화, 협력적 미술활동이 각각 1 편 $(1.5 \%)$ 순으로 나 타났다. 부모를 대상으로 개발된 프로그램은 e-learning 기반 프로그램과 솦 프로그램이 각각 1편(1.5\%)으로 나타났다. 교 
Table 7

Research Trends in Practical Research by Subject

\begin{tabular}{|c|c|c|c|c|c|c|c|c|c|c|}
\hline $\begin{array}{ll}\text { Division } & \text { Year }\end{array}$ & 2008 & 2009 & 2010 & 2011 & 2012 & 2013 & 2014 & 2015 & 2016 & Sum \\
\hline \multicolumn{11}{|c|}{ Program development and effectiveness } \\
\hline \multicolumn{11}{|l|}{ Young children } \\
\hline Happiness education & & & & & & & 1 & 3 & & $4(6.3)$ \\
\hline Picture book & 1 & & & & & & 5 & 5 & 1 & $12(19.0)$ \\
\hline Nuri course & & & & & & & & & 2 & $2(3.1)$ \\
\hline Green food life & & & & & & & & & 1 & $1(1.5)$ \\
\hline Forest program & & & & & 1 & 3 & 1 & & 1 & $6(9.5)$ \\
\hline Personality education & & & & & & & & 1 & & $1(1.5)$ \\
\hline Nature friendship & & & & 2 & & 1 & & 3 & 3 & $9(14.2)$ \\
\hline Traditional play & & & & & & & & 4 & & $4(6.3)$ \\
\hline Outdoor play & & & & & & & & 2 & & $2(3.1)$ \\
\hline Traditional stories & & & & & & & & 1 & & $1(1.5)$ \\
\hline Music activity & & & & & & & & 1 & 2 & $3(4.7)$ \\
\hline $\begin{array}{l}\text { Cooperative art } \\
\text { activities }\end{array}$ & & & & & & 1 & & & & $1(1.5)$ \\
\hline \multicolumn{11}{|l|}{ Parents } \\
\hline $\begin{array}{l}\text { Parent education based } \\
\text { on e-learning }\end{array}$ & & & & & & & 1 & & & $1(1.5)$ \\
\hline Forest program & & & & & & & & 1 & & $1(1.5)$ \\
\hline \multicolumn{11}{|l|}{ Teachers } \\
\hline Forest program & & & & & & 1 & & & & $1(1.5)$ \\
\hline $\begin{array}{l}\text { Cooperative health } \\
\text { program }\end{array}$ & & & & & & 1 & & & & $1(1.5)$ \\
\hline Happy flourish & & & & & & & & & 1 & $1(1.5)$ \\
\hline Happiness promotion & & 1 & & & 1 & & & 1 & 1 & $4(6.3)$ \\
\hline Happy training & & & & & & & & 1 & & $1(1.5)$ \\
\hline Thanks diary & & & & & & 1 & & & & $1(1.5)$ \\
\hline Sum & 1 & 1 & & 2 & 2 & 8 & 8 & 23 & 12 & $57(90.4)$ \\
\hline
\end{tabular}

Scale development

Young children

Basic research

Scale development

1

Teachers

Scale development

Sum

1

$\begin{array}{lll}1 & 2 & 2\end{array}$

$6(9.5)$

\begin{tabular}{lllllllllll}
\hline Total & $1(1.5)$ & $1(1.5)$ & $1(1.5)$ & $2(3.1)$ & $2(3.1)$ & $8(12.6)$ & $9(14.2)$ & $25(39.6)$ & $14(22.2)$ & $63(100.0)$ \\
\hline
\end{tabular}

Note. $N=63 . \mathrm{a}=$ young children; $\mathrm{b}=$ parents; $\mathrm{c}=$ teachers. Numbers in brackets represent percentages.

사를 대상으로 개발된 프로그램 중 행복증진 프로그램이 4편 (6.3\%)으로 가장 많이 나타났으며, 다음으로 숲 프로그램, 협 력중심 건강 프로그램, 행복플로리시, 행복연수, 감사일기 프 로그램이 각각 1 편(1.5\%)으로 나타났다. 이러한 결과를 통해
행복 프로그램은 영·유아를 대상으로 개발된 프로그램이 가장 많고, 그 중 그림책을 활용한 프로그램이 많이 개발되었으며, 부모를 대상으로 개발된 프로그램이 가장 적음을 알 수 있다. 다음으로 척도개발에 대한 연구동향을 연구대상에 따라 살펴 
Table 8

Research Trends in Practical Research (Young Children)

\begin{tabular}{|c|c|c|c|c|c|c|c|c|c|c|}
\hline Division & 2008 & 2009 & 2010 & 2011 & 2012 & 2013 & 2014 & 2015 & 2016 & Sum \\
\hline \multicolumn{11}{|l|}{ Demographic } \\
\hline Temperament & & & & & & & & 4 & & $4(1.6)$ \\
\hline Age & & & & & & & & 2 & & $2(0.8)$ \\
\hline Gender & & & & & 1 & & & 2 & & $3(1.2)$ \\
\hline \multicolumn{11}{|l|}{ Cognitive } \\
\hline Creativity & & & & & 1 & & & & & $1(0.4)$ \\
\hline \multicolumn{11}{|l|}{ Emotional } \\
\hline Vessel & & & & & & & 1 & & & $1(0.4)$ \\
\hline Self-esteem & & & & & & & 1 & 2 & & $3(1.2)$ \\
\hline \multicolumn{11}{|l|}{ Social } \\
\hline Solving the great human problem & & & 1 & & & & & & & $1(0.4)$ \\
\hline Kindergarten adaptation & & & & 1 & & & 1 & 1 & & $3(1.2)$ \\
\hline Leadership & & & & & & & 2 & & & $2(0.8)$ \\
\hline Peer competence & & & & & & 1 & & 1 & & $2(0.8)$ \\
\hline Social support & & & & & & & & 1 & & $1(0.4)$ \\
\hline \multicolumn{11}{|l|}{ Moral } \\
\hline Problem behavior & & & & 1 & & & & 1 & & $2(0.8)$ \\
\hline
\end{tabular}

Note. $N=36$. Numbers in brackets represent percentages.

보면, 유아를 대상으로 한 기초연구는 2 편(3.1\%)이며, 척도개 발은 1 편(1.5\%)으로 나타났고, 교사를 대상으로 한 척도개발 은 3편(4.7\%)으로 나타났다. 이를 통해 유아와 교사를 대상으 로 한 척도개발연구는 진행되었으나 영아나 부모를 대상으로 한 행복 척도개발은 아직 이루어지지 않았음을 알 수 있다. 연 구주제의 실천연구 중 변인의 연구동향을 연구대상별로 살펴 보면 Table 8, 9, 10 과 같다.

Table $8,9,10$ 과 같이 연구주제의 실천연구 중 변인의 연 구동향을 연구대상별로 살펴보면, 교사변인에 대한 연구가 159 편(64.9\%)으로 가장 많이 이루어졌으며, 부모변인 50편 (20.4\%), 유아변인 36편(14.7\%) 순으로 나타났다. 교사행복과 관련된 변인 중 인구통계 변인에서는 성격강점이 6편(2.4\%) 으로 가장 많이 나타났으며, 그 다음 근무유형이 4편(1.6\%), 교직적성이 3 편(1.2\%), 학력과 자질이 각각 2편(0.8\%), 연령 과 경력이 각각 1 편 $(0.4 \%)$ 순으로 나타났다. 인지 변인에서는
교수몰입이 13편(5.3\%)으로 가장 많이 나타났으며, 그 다음 창의성이 7편(2.8\%), 조직몰입이 5편(2.0\%), 임파워먼트가 4 편(1.6\%), 교육신념이 3편(1.2\%), 자기개발과 전문성인식, 자 기결정이 각각 1 편 $(0.4 \%)$ 순으로 나타났다. 정서 변인에서는 교사효능감이 27편(11.0\%)으로 가장 많이 나타났으며, 그 다 음 직무만족이 15 편(6.1\%), 자아탄력성이 9편(3.6\%), 자아존 중감이 7편(2.8\%), 감사성향이 4편(1.6\%), 심리적 소진이 3편 $(1.2 \%)$, 정서노동이 2 편( $0.8 \%)$, 긍정적정서가 1 편(0.4\%) 순으 로 나타났다. 사회 변인에서는 스트레스가 8편(3.2\%)으로 가 장 많이 나타났으며, 그 다음 상호작용이 7편(2.8\%), 이직의도 와 셀프리더십이 각각 3 편(1.2\%), 대인관계유능성과 유머가 각각 2 편 $(0.8 \%)$, 공감능력과 적응유연성, 역할수행, 사회적지 지가 각각 1 편 $(0.4 \%)$ 순으로 나타났다. 도덕 변인에서는 영아 문제행동이 1 편( $0.4 \%)$ 으로 나타났다. 이를 통해 변인에서 교 사행복과 관련된 연구 중 교사효능감과 직무만족, 교수몰입에 
Table 9

Research Trends in Practical Research (Parents)

\begin{tabular}{|c|c|c|c|c|c|c|c|c|c|c|}
\hline 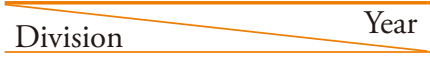 & 2008 & 2009 & 2010 & 2011 & 2012 & 2013 & 2014 & 2015 & 2016 & Sum \\
\hline \multicolumn{11}{|l|}{ Demographic } \\
\hline Academic background & & & & & & & 1 & 2 & & $3(1.2)$ \\
\hline Economic strength & & & & & & & 1 & 2 & & $3(1.2)$ \\
\hline Occupation & & & & & & & 1 & 2 & 1 & $4(1.6)$ \\
\hline Personality traits & & & & & & & 2 & 1 & & $3(1.2)$ \\
\hline Attachment & & 1 & & & & & & & & $1(0.4)$ \\
\hline Age & & & & & & & & 1 & & $1(0.4)$ \\
\hline \multicolumn{11}{|l|}{ Cognitive } \\
\hline Ability & & & & & & & 1 & & & $1(0.4)$ \\
\hline Coaching & & & & & & & & & 1 & $1(0.4)$ \\
\hline \multicolumn{11}{|l|}{ Emotional } \\
\hline Resilience & & & & & & & & & 1 & $1(0.4)$ \\
\hline Young children happiness & 1 & 2 & & & & & & & & $3(1.2)$ \\
\hline Job satisfaction & & & & & & & & & 1 & $1(0.4)$ \\
\hline Parenting efficacy & & & & & & 1 & 1 & & 2 & $4(1.6)$ \\
\hline Parenting stress & & & & & & & & & 3 & $3(1.2)$ \\
\hline Parent satisfaction & & & & & & & & 1 & 1 & $2(0.8)$ \\
\hline Stroke type & & & & & & & & 1 & & $1(0.4)$ \\
\hline \multicolumn{11}{|l|}{ Social } \\
\hline Marital relationship & & & & & & & 2 & 2 & & $4(1.6)$ \\
\hline Parenting attitude & & & & & & 1 & 1 & 3 & 2 & $7(2.8)$ \\
\hline Participation in play & & & & & 1 & & & 2 & 1 & $4(1.6)$ \\
\hline Child relationship & & & & & & & 1 & & & $1(0.4)$ \\
\hline Empathy ability & & & & & & & & & 1 & $1(0.4)$ \\
\hline Participation in parenting & & & & & & & 1 & & & $1(0.4)$ \\
\hline Total & $1(0.4)$ & $3(1.2)$ & & & $1(0.4)$ & $2(0.8)$ & $12(4.8)$ & $17(6.9)$ & $14(6.1)$ & $50(20.4)$ \\
\hline
\end{tabular}

Note. $N=50$. Numbers in brackets represent percentages.

대한 연구가 가장 많이 이루어졌음을 알 수 있다.

다음으로 부모행복과 관련된 변인 중 인구통계 변인에서는 직업이 4 편(1.6\%)으로 가장 많이 나타났으며, 그 다음 학력과 경제력, 성격특성이 각각 3 편(1.2\%), 애착과 연령이 각각 1 편 $(0.4 \%)$ 순으로 나타났다. 인지 변인에서는 부모역량과 코칭이 각각 1 편( $0.4 \%)$ 으로 나타났으며, 정서 변인에서는 양육효능 감이 4편(1.6\%)으로 가장 많이 나타났고, 그 다음 영·유아 행 복과 양육스트레스가 각각 3편(1.2\%), 부모만족이 2편(0.8\%), 회복탄력성과 직무만족, 스트로크유형이 각각 1 편(0.4\%) 순 으로 나타났다. 사회 변인에서는 양육태도가 7편(2.8\%)으로 가장 많이 나타났으며, 그 다음 부부관계와 놀이참여가 각각 4 편(1.6\%), 자녀관계와 공감능력, 양육참여가 각각 1 편(0.4\%)
순으로 나타났다. 이를 통해 변인에서 부모행복과 관련된 연 구 중 양육태도와 직업, 양육효능감, 부부관계, 놀이참여에 대 한 연구가 가장 많이 이루어졌음을 알 수 있다.

또한 유아 행복과 관련된 변인 중 인구통계 변인에서는 기 질이 4편(1.6\%)으로 가장 많이 나타났으며, 그 다음 성별 3편 (1.2\%), 연령 2 편(0.8\%), 애착과 출생순위가 각각 1 편(0.4\%) 순으로 나타났다. 인지 변인에서는 창의성이 1 편( $0.4 \%)$ 으로 나타났고, 정서 변인에서는 정서지능이 4편(1.6\%)으로 가장 많이 나타났으며, 그 다음 자아존중감과 자아탄력성이 각각 3 편(1.2\%), 용기와 감사성향이 각각 1 편 $(0.4 \%)$ 순으로 나타났 다. 사회 변인에서는 유치원적응이 3 편(1.2\%)으로 가장 많이 나타났으며, 그 다음 리더십과 또래유능성이 각각 2 편( $0.8 \%)$, 
Table 10

Research Trends in Practical Research (Teachers)

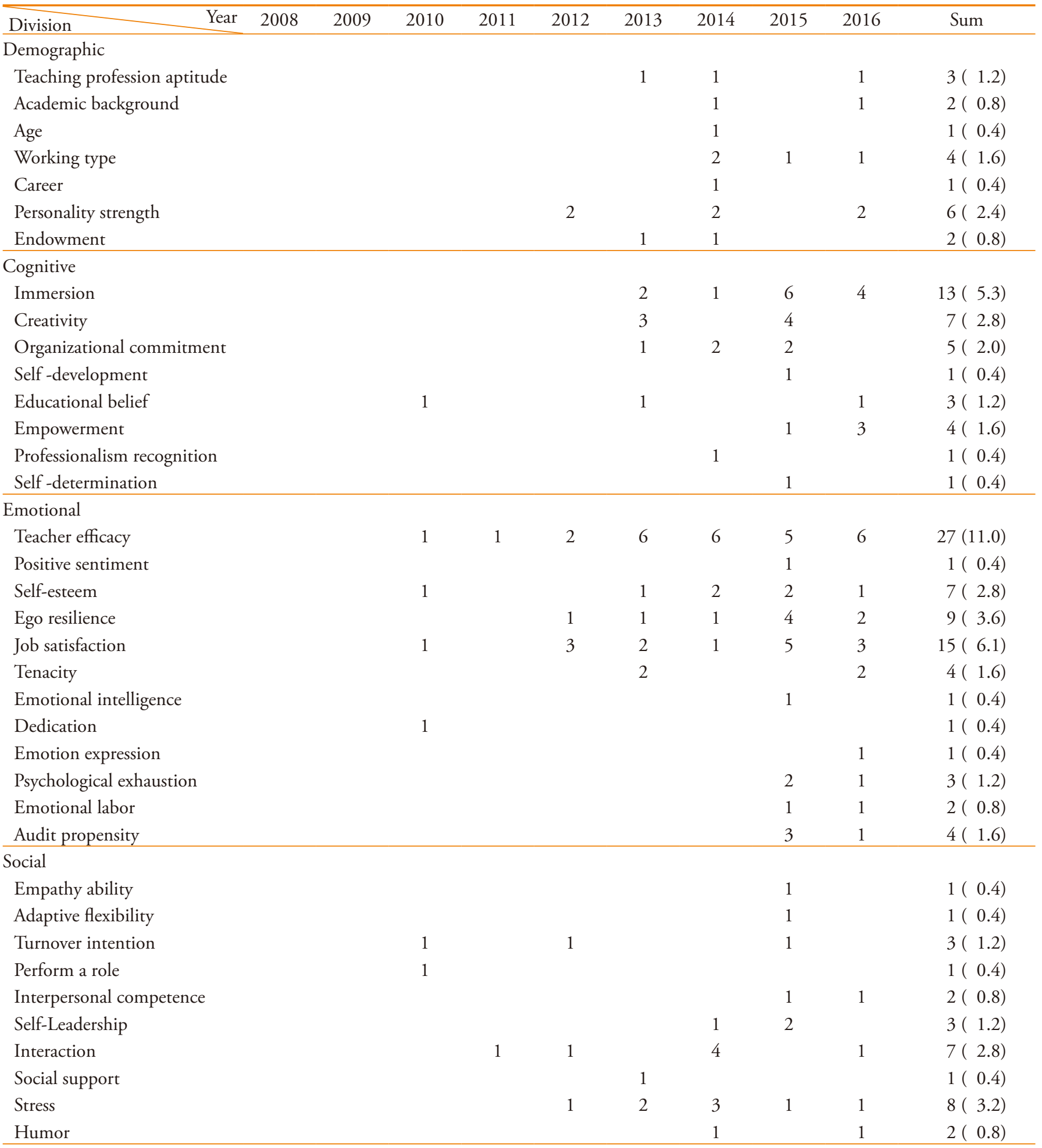

Moral

Infant problem behavior

1

$1(0.4)$

Total

$7(2.8)$

$159(64.9)$

Note. $N=159$. Numbers in brackets represent percentages. 
Table 11

Research Trends According to Research Methods

\begin{tabular}{|c|c|c|c|c|c|c|c|c|c|c|}
\hline $\begin{array}{ll}\text { Division } & \text { Year } \\
\end{array}$ & 2008 & 2009 & 2010 & 2011 & 2012 & 2013 & 2014 & 2015 & 2016 & Sum \\
\hline \multicolumn{11}{|l|}{ Quantitative research } \\
\hline Experimental & 1 & & & 1 & 1 & 5 & 7 & 18 & 11 & $44(18.0)$ \\
\hline Survey & & & 2 & 2 & 3 & 5 & 13 & 26 & 17 & $68(27.9)$ \\
\hline Correlation & 1 & 3 & 2 & 3 & 7 & 11 & 20 & 22 & 23 & $92(37.7)$ \\
\hline Sum & 2 & 3 & 4 & 6 & 11 & 21 & 40 & 66 & 51 & $204(83.6)$ \\
\hline \multicolumn{11}{|l|}{ Qualitative research } \\
\hline Ethnographic & & & & & 1 & & & 2 & & $3(1.2)$ \\
\hline Narrative & & & & & 1 & 1 & & 2 & & $4(1.6)$ \\
\hline In-depth interview & & 1 & 1 & & & 2 & 1 & 4 & 3 & $12(4.9)$ \\
\hline Sum & & 1 & 1 & & 2 & 3 & 1 & 8 & 3 & $19(7.8)$ \\
\hline Literature & & 3 & & 1 & & 3 & 2 & 2 & 2 & $13(5.3)$ \\
\hline Multiple & & 1 & 1 & & 1 & 2 & 2 & & 2 & $9(3.7)$ \\
\hline Total & $2(0.8)$ & $8(3.3)$ & $6(2.5)$ & $7(2.9)$ & $14(5.7)$ & $29(11.9)$ & $45(18.4)$ & $76(31.1)$ & $58(23.6)$ & $245(100.0)$ \\
\hline
\end{tabular}

Note. $N=245$. Numbers in brackets represent percentages.

Table 12

Research Trends According to Subjects

\begin{tabular}{|c|c|c|c|c|c|c|c|c|c|c|}
\hline Division Year & 2008 & 2009 & 2010 & 2011 & 2012 & 2013 & 2014 & 2015 & 2016 & Sum \\
\hline \multicolumn{11}{|l|}{ Young children } \\
\hline 1-year-old & & & & & 1 & & & & & $1(0.3)$ \\
\hline 2-year-old & & & & & 1 & & & & 1 & $2(\quad 0.6)$ \\
\hline 3 -year-old & & 2 & & & 1 & 1 & 2 & 2 & 5 & $13(3.7)$ \\
\hline 4-year-old & 1 & 3 & 2 & 3 & 2 & 5 & 7 & 15 & 11 & $49(14.0)$ \\
\hline 5-year-old & 2 & 3 & 2 & 2 & 5 & 11 & 14 & 30 & 20 & $89(25.3)$ \\
\hline Sum & 3 & 8 & 4 & 5 & 10 & 17 & 23 & 47 & 37 & $154(43.9)$ \\
\hline \multicolumn{11}{|l|}{ Parents } \\
\hline Mother & 1 & 2 & & 2 & 5 & 4 & 8 & 8 & 15 & $45(12.8)$ \\
\hline Father & 1 & & & & & 1 & 5 & 5 & 5 & $17(4.9)$ \\
\hline Sum & 2 & 2 & & 2 & 5 & 5 & 13 & 13 & 20 & $62(17.7)$ \\
\hline \multicolumn{11}{|l|}{ Teachers } \\
\hline Preliminary & & & 2 & & 3 & 2 & 2 & 7 & 3 & $19(5.4)$ \\
\hline Incumbent & & 1 & 2 & 2 & 5 & 11 & 25 & 32 & 26 & $104(29.6)$ \\
\hline Sum & & 1 & 4 & 2 & 8 & 13 & 27 & 39 & 29 & $123(35.0)$ \\
\hline Literature & & 3 & & 1 & & 3 & 2 & 2 & 1 & $12(3.4)$ \\
\hline Total & $5(1.4)$ & $14(4.0)$ & $8(2.3)$ & $10(2.8)$ & $23(6.5)$ & $38(10.8)$ & $65(18.5)$ & $101(28.8)$ & $87(24.8)$ & $351(100.0)$ \\
\hline
\end{tabular}

Note. Duplicate response was allowed. Numbers in brackets represent percentages.

대인간 문제해결과 사회적지지가 각각 1 편(0.4\%) 순으로 나 타났다. 도덕 변인에서는 문제행동이 2편( $0.8 \%)$, 도덕적 판단 력이 1 편 $(0.4 \%)$ 순으로 나타났다. 이를 통해 변인에서 영·유아 행복과 관련된 연구 중 기질과 정서지능에 대한 연구가 가장 많이 이루어졌음을 알 수 있다.

\section{연구방법에 따른 연구동향}

연구방법에 따른 연구동향을 분석한 결과는 Table 11 과 같다.

Table 11과 같이 연구방법에 따른 연구동향을 살펴보면, 양 적연구가 204편(83.6\%)으로 가장 많이 이루어졌으며, 그 다 
음 질적연구 19편(7.8\%), 문헌연구 13편(5.3\%), 다중연구 9편 (3.7\%) 순으로 나타났다. 이를 자세히 살펴보면, 양적연구는 변인간의 관계를 분석 또는 예측하는 방법인 상관연구가 92 편 (37.7\%)으로 가장 많이 이루어졌으며, 그 다음 설문을 통해 자 료를 수집하여 분석하는 조사연구 68편(27.9\%), 이론에 근거 한 가설을 검증하는 실험연구 44 편(18.0\%) 순으로 나타났다. 질적 연구는 면담과 관찰을 통해 이루어지는 심층면담이 12 편(4.9\%)으로 가장 많이 이루어졌으며, 그 다음 주요 장면을 관찰하여 줄거리를 서술하는 연구방법인 내러티브 연구 4편 (1.6\%), 어린이집 혹은 유치원의 현장으로 들어가 그들의 문 화를 관찰 기록하는 연구방법인 문화기술 연구 3편(1.2\%) 순 으로 나타났다. 이를 통해 연구방법 중 양적연구는 많이 이루 어진 반면 질적연구와 문헌연구, 다중연구는 상대적으로 적게 이루어졌음을 알 수 있다.

\section{연구대상에 따른 연구동향}

연구대상에 따른 연구동향을 살펴보면 Table 12 와 같다.

Table 12 와 같이 연구대상에 따른 연구동향을 살펴보면, 영. 유아 대상 연구가 154 편(43.9\%)으로 가장 많이 이루어졌으며, 그 다음 교사 대상 연구가 123편(35.0\%), 부모 대상 연구가 62 편(17.7\%), 문헌 대상 연구가 12편(3.4\%) 순으로 나타났다. 이 를 자세히 살펴보면, 영·유아 대상 연구 중 만 5세를 대상으로 한 연구가 89편(25.3\%)으로 가장 많이 나타났으며, 그 다음 만 4세 49편(14.0\%), 만 3세 13편(3.7\%), 만 2세 2편(0.6\%), 만 1세 1 편 $(0.3 \%)$ 순으로 나타났다. 부모 대상 연구 중 유아 어머니 대상 연구가 40 편(11.4\%)로 가장 많이 나타났으며, 그 다음 유 아 아버지 대상 연구가 16 편(4.6\%), 영아 어머니 대상 연구가 5 편(1.4\%), 영아 아버지 대상 연구가 1편(0.3\%) 순으로 나타났 다. 교사 대상 연구 중 현직교사를 대상으로 한 연구가 104편 (29.6\%), 예비교사를 대상으로 한 연구가 19편(5.4\%)으로 나 타났다. 이를 통해 연령이 높은 유아를 대상으로 한 연구가 영 아를 대상으로 한 연구보다 더 많이 이루어졌으며, 부모 또한 유아부모를 대상으로 한 연구가 영아부모를 대상으로 한 연구 보다 많이 이루어졌음을 알 수 있다. 또한 교사를 예비교사와 현직교사로 나누어살펴보았을 때, 현직교사를 대상으로 한 연 구가 많이 이루어졌음을 알 수 있다.

\section{논의 및 결론}

이 연구는 영·유아와 영·유아 행복에 결정적 영향을 미치는 부모, 교사의 행복에 관한 연구들의 동향을 함께 분석해봄으 로써, 전반적인 행복 연구의 흐름을 파악하여 영·유아 행복 연구의 기초를 마련해 앞으로 이루어질 행복 연구의 방향을 제시해 주는데 그 목적이 있다.

이러한 연구목적에 의해 2008년에서 2016년까지 영·유아 와 부모, 교사를 대상으로 한 학위 및 학술논문 245 편을 분석 하여 도출한 논의 및 결론은 다음과 같다.

첫째, 영·유아 행복 연구의 연구시기별 동향을 살펴본 결 과, 2008년도에 영·유아 행복 연구 2편이 처음 등장하였으며, 이후 연구의 양이 서서히 증가하다 2013년도에 30편의 연구 를 시작으로 2014년도에 45편, 2015년도에 79편, 2016년도에 58 편의 연구가 이루어졌다. 이를 통해 영·유아 행복 관련 연구 가 꾸준히 증가하고 있음을 알 수 있다. 이는 행복관련 연구가 2009년부터 꾸준히 증가하다 2012년 이후부터 급증하기 시작 했다고 한 Kang (2014)의 연구와 맥락을 같이 한다. 2013년도 부터 영·유아 행복 관련 연구가 급증한 이유는 같은 해 2월 출 범한 정부가 국정과제로 국민행복을 제시하며, 이를 강조한 것에서 찾아볼 수 있을 것이다(M. Kim et al, 2013). 또한 정부 는 '꿈과 끼를 키우는 행복교육'을 제시하며 실질적인 행복교 육이 학교 현장에서 이루어질 수 있도록 다양한 지원을 하였 으며, 이러한 과정을 통해 영·유아와 행복에 대한 연구 활동이 활발하게 이루어진 것으로 풀이될 수 있다. 영·유아 행복교육 이 최근 들어 급증한 또 다른 이유는 행복감의 감소와 그에 따 른 다양한 사회적 문제의 증가 (학교폭력, 묻지마 범죄, 성폭 행, 인신매매, 미혼모 증가, 사회문제의 저연령화 등)와 긍정 심리학의 등장에서 찾을 수 있다. 갈수록 피폐해져 가는 사회 에서 행복감의 증가는 사람들의 정서를 순화시켜 범죄를 감소 시키고 행복한 사회를 만들 수 있을 것이라는 기대감으로 이 어졌다. 이러한 생각과 맞물려 등장한 긍정심리학은 인간의 긍정적인 측면에 초점을 맞춤으로써 개인의 행복을 증진시킬 수 있는 방법을 과학적으로 탐구하여 그와 관련된 연구가 활 발히 이루어지는데 일조하였다. 이렇듯 다양한 원인들이 맞물 려 영·유아 행복 연구의 수가 갈수록 증가하고 있으며 이러한 현상이 지속적으로 유지될 수 있도록 추후 국가적인 차원에서 영 - 유아 행복에 대한 많은 관심을 가지고 지속적인 지원이 이 루어져야 할 필요성이 있다.

둘째, 영·유아 행복 연구의 연구주제별 동향을 살펴본 결 과, 기초연구 36 편, 실천연구 228 편으로 실천연구가 많이 이 
루어졌음을 알 수 있다. 물론 실천연구를 통해 현장에 직접 적 용 가능한 프로그램들을 개발할 수 있기 때문에 그 수가 많을 수록 좋을 것이다. 하지만 실천연구가 탄탄한 이론적 틀에 기 반을 두고 이루어지지 않는다면 현장에서 적용이 어렵거나 최 대의 효과를 기대하기 어려울 것이다. 그 예로, 영·유아는 개 월 수에 따라, 혹은 발달 특성에 따라 개인차가 발생하게 되므 로, 영·유아의 발달에 대한 연구가 심도 있게 이루어진 후에 영 · 유아의 발달에 맞는 행복 교육 프로그램 개발이 이루어져 야 만이 현장에서 적용 가능한 실질적인 프로그램이 개발될 수 있을 것이다. 따라서 추후 영·유아 행복에 대한 기초연구 가 다양하게 이루어져 실천연구들의 기틀을 마련할 필요성이 있다. 이를 더 자세히 살펴보면, 기초연구는 인식 - 실태 22편, 동향연구 11 편, 이론연구 5편 순으로 이루어졌으며, 이를 통 해 이론연구의 수가 적음을 알 수 있다. 또한 실천연구는 변인 연구 159 편, 프로그램 개발 및 효과 연구 57편, 척도개발 연구 6 편 순으로 이루어졌으며, 이를 통해 척도개발 연구의 수가 적 음을 알 수 있다. 더구나 유아, 부모, 교사용 행복 척도개발은 이루어졌으나 영아 대상 혹은 영·유아가 함께 측정할 수 있 는 척도개발은 이루어지지 않고 있다. 측정도구를 통해 현재 영 - 유아의 행복지수를 파악함으로써 개별적으로 그들에게 적합한 행복교육 프로그램을 개발할 수 있으므로, 영아 대상 척도개발이 이루어질 필요성이 있다. Song (2014)은 유아교사 행복관련 연구에서 자료수집방법으로 검사 및 척도를 활용한 연구가 가장 많았고, 앞으로 행복 관련 연구 증진을 위해 행복 감 측정도구 개발에 관한 연구가 필요함을 이야기하였고, G. Y. Kim (2017) 또한 영아 행복과 관련된 연구가 이루어지지 않 고 있는 이유를 측정도구 선정이 어렵기 때문이라 하며 이 연 구의 결과를 이론적으로 뒷받침해준다.

셋째, 영·유아 행복 연구의 연구방법별 동향을 살펴본 결 과, 양적연구가 가장 많이 이루어졌으며, 질적연구, 문헌연구, 다중연구는 상대적으로 적게 이루어졌음을 알 수 있다. 이는 Shin과 Choi (2014)의 연구에서 행복 관련 연구의 분석 결과 양 적연구가 가장 많이 이루어졌다고 한 부분과 맥락을 같이하나 질적연구는 단 2편만 이루어졌다고 한 결과와는 다른 양상을 보인다. 그 이유는 그들의 연구가 2000년부터 2013년까지 이 루어진 연구들을 대상으로 분석한 것에서 기인한 것으로 보인 다. 이 연구는 2008년에서 2016년까지 이루어진 연구들을 대 상으로 하였으며, 질적연구의 양은 2015년부터 급증한 것으 로 나타났기 때문이다. 최근 들어 질적연구의 양이 급증하였 다고는 하나 양적연구에 비해 그 수가 턱없이 부족한 것이 사 실이다. 행복은 본질적으로 지극히 주관적인 긍정적 느낌에서
비롯되므로, 단순한 수치의 계산을 통해 이루어지는 양적연구 로는 영·유아 개인의 행복을 온전히 이해하기에 그 한계가 있 을 수 있다. 따라서 단순히 양적인 연구가 아닌 유아교육현장 에서 영·유아의 생활모습을 직접 관찰·기록하며, 그들의 삶 속 으로 들어가 개개인의 주관적 행복의 의미를 도출할 수 있는 질적연구가 더욱 활발히 이루어져야 할 필요성이 있다.

넷째, 영·유아 행복 연구의 연구대상별 동향을 살펴본 결 과, 영 · 유아 대상 연구가 가장 많이 이루어졌으며, 그 다음 교 사 대상 연구, 부모 대상 연구, 문헌 대상 연구 순으로 나타났 다. 이는 H. K. Kang (2014)의 연구에서 행복 관련 논문의 연구 대상이 교사, 부모, 유아, 예비교사, 문헌 순으로 나타난 것과 의견을 달리한다. 이 연구의 분석결과 유아 대상 연구는 2015 년부터 2016년까지 그 수가 급격히 증가한 것으로 나타났으 므로, 위와 같은 현상의 이유를 연구기간의 차이에서 기인한 것으로 볼 수 있다. 또한 유아 대상 연구가 영아 대상 연구보 다 훨씬 더 많은 비중을 차지하며, 부모 또한 유아부모 대상 연구가 영아부모 대상 연구보다 많은 비중을 차지하고 있었 다. 이는 행복 연구에서 영아부모보다는 유아부모를 대상으로 한 연구가 많았다고 한 K. Lee, Yoon과 Byeon (2016)의 연구결 과와 맥락을 같이한다. 이렇듯 행복 연구에서 영아보다 유아 를 대상으로 한 연구가 많은 이유는 유아의 발달특성 상 행복 에 대한 가치를 이해하고 표현하는 데 한계를 가지고 있으며 (Y. Kim, 2011), 이러한 한계는 영아에게서 더 뚜렷이 나타나기 때문인 것으로 풀이된다. 또 다른 이유로 영아기 행복감의 중 요성과 영아 발달의 중요성에 대한 성인의 인식부족을 들 수 있다. 아이가 태어나고 초기 3년인 영아기는 신체·언어·정 서·인지·사회의 모든 영역에서 급격한 변화를 겪기 때문에, 가장 많은 변화의 가능성을 가지고 있으므로 그 어느 때보다 많은 교육이 이루어져야 한다. 또한 이 초기 3 년의 경험은 영 아의 미래에 지속적인 영향을 미치기 때문에 영아기 행복 교 육은 행복한 성인이 될 수 있는 밑거름을 제공하므로 유아기 행복 못지않게 중요하게 다루어져야 할 주제이다. 따라서 추 후 영아와 영아부모, 교사를 대상으로 한 행복 관련 연구가 지 속적으로 이루어져야 할 필요성이 있다.

마지막으로 교사를 예비교사와 현직교사로 나누어 살펴보 았을 때, 현직교사를 대상으로 한 연구가 많이 이루어졌음을 알 수 있다. 이는 유아교사의 행복 관련 연구에서 예비교사 대 상 연구보다 보육교사 대상 연구가 많이 이루어졌으나 예비교 사 대상 연구가 점차 증가하고 있는 추세라고 이야기한 M. S. Song (2014)의 연구와 맥락을 같이 한다. 앞으로 유아교육현장 에서 유아의 발달을 책임지는 현직교사가 될 예비유아교사의 
행복감 또한 중요하게 다루어져야 할 연구 분야일 것이다.

이 연구의 분석결과를 토대로 영·유아 행복 관련 후속연구 에 대한 제언을 하면 다음과 같다.

첫째, 이 연구는 '영·유아 행복' '영 · 유아 행복-부모', ‘영 · 유아 행복-교사'를 키워드로 검색하여 나타난 연구를 중 심으로 분석하여 행복과 유사한 용어들로 이루어진 연구가 포 함되지 못한 한계점이 있다. 따라서 추후연구에서는 '긍정심 리, 심리적 안녕, 삶의 만족' 등 행복과 유사한 용어로 이루어 진 연구들을 함께 분석하여 광범위한 행복 연구동향을 파악할 필요성이 있다.

둘째, 이 연구는 대다수의 사람들에게 접근이 용이한 학 회 - 학술논문을 중심으로 연구가 이루어졌다. 따라서 추후연 구에서는 유아 행복과 관련하여 발간된 자료 또는 국제자료를 포함한 연구가 이루어져야 할 필요성이 있다.

셋째, 영·유아기에 느끼는 행복감은 아이들의 현재와 미 래에 중요한 영향을 미친다. 그럼에도 불구하고 현재까지 영 아기의 행복감에 대한 연구는 매우 미흡한 실정이며, 이는 영 아기 행복감을 측정할 수 있는 척도가 아직 개발되지 않은 것 에서 기인한 것으로 보인다. 따라서 추후 연구를 통해 영아기 행복감을 측정할 수 있는 척도가 개발되어져야 할 필요성이 있다.

넷째, 행복은 본질적으로 지극히 개인적이며 주관적인 긍 정적 느낌에서 비롯된다. 그러므로 영 · 유아 행복에 관한 연구 는 그들의 삶 속에서 관찰과 면담, 그림 분석 등의 질적 분석을 통해 이루어져야 할 것이다. 따라서 추후 영·유아 행복에 대 한 연구는 질적방법을 통해 이루어져야 할 필요성이 있다.

\section{Conflict of Interest}

No potential conflict of interest relevant to this article was reported.

\section{References}

\section{In English}

Helliwell, J., Layard, R., \& Sachs, J. (2017). World Happiness Report 2017. New York: Sustainable Development Solutions Network.

Yang, Y. (2008). Social inequalities in happiness in the United
States, 1972 to 2004: An age-period-cohort analysis. American Sociological Review, 73(2), 204-226.

\section{In Korean}

Choe, S. (2015). A structural relationship between young children's happiness and its variables: Temperament, parenting efficacy and ego-resilience (Doctoral dissertation). Retrieved from http://www.riss.kr/link?id=T13837623

Choi, E. A., \& Chung, K. S. (2015). The process of meaning construction on children's happiness by mothers with young children. Korean Journal of Childcare and Education, 11(5), 261-292. doi:10.14698/jkcce.2015.11.261

Do, N., Bae, Y.-J., \& Kim, J. (2014). Yuagi haengbokgam jeungjin bangan[유아기 행복감 증진 방안] (Report No. 2014-21). Seoul: Korea Institute of Child Care and Education.

Gwon, G. N., \& Sung, M. (2010). The influences of young children's happiness on behavior problems and interpersonal problem solving strategies. Korean Journal of Human Ecology, 19(2), 257-270.

Ha, K. (2016). The effects of work-family balance and resilience on happiness in dual-earner couples with early childhood: The mediating effects of parenting self-efficacy and job satisfaction (Doctoral dissertation). Retrieved from http://www.riss.kr/ link?id=T14180439

Hwang, H., Nam, M., Seo, B., \& Kim, B. (2016). Adonggwolliwa bokji[아동권리와 복지]. Gyeonggi: Jeongminsa.

Hwang, H.-I., \& Kim, E.-J. (2016). Path analysis of the influential factors for the happiness of young children teachers. Korea Journal of Early Childhood Education, 36(5), 373-397. doi:10.18023/kjece.2016.36.5.015

Kang, H.-K. (2014). The trends of studies on happiness in early childhood education. Korea Journal of Child Care and Education, 89, 1-28.

Kang, Y. W. (2009). A study on young children's happiness and understanding of happiness concept. The Journal of Hanyoung Theological University, 13, 451-477.

Kim, Y. (2011). The influence of the nature play activities on children's happiness and self-concept (Master's thesis). Retrieved from http://www.riss.kr/link?id=T12400331

Kim, D.-R., \& Kim, J. (2008). Study of the correlation between the happiness of young children and that of their parents. The Journal Korea Open Association for Early Childhood Education, 13(6), 311-333.

Kim, G.-Y. (2017). A study on the infant teachers' perception and demand of the infant's happiness and the happiness enhancement activity (Master's thesis). Retrieved from http://www.riss.kr/link?id=T14587301

Kim, I. (2011). Tendency analysis of study for happiness of 
children. Sookmyung Journal of Child Study, 24(1), 23-42.

Kim, J., \& Bang, S. (2014). The development and practical application of a literature program for the improvement of young children's happiness: Using Tasha Tudor's picture books. Journal of Children's Literature and Education, 15(3), 93-114.

Kim, M., Kim, C. M., Lee, Y., Kwon, S. M., Kwon, Y. S., \& Lee, S. (2013). 21st Century global trends in education reform (I): Education for Happiness (Report No. 2013-17). Seoul: Korean Educational Development Institute.

Kim, M.-J., \& Kim, B.-M. (2012). Narrative inquiry on early childhood teachers' happiness in the eco-early childhood education field. The Journal of Eco-Early Childhood Education \& Care, 11(2), 29-55.

Kim, S. B. (2012). Study on young children's happiness based on ecological family variables (Master's thesis). Retrieved from http://www.riss.kr/link?id=T12654854

Kim, S. H., \& Kang, S. M. (2008). The expansion of the concept of happiness of five-year-olds by sharing picture books that deal with the topic of psychological well-being. Journal of Children's Literature and Education, 9(2), 119-139.

Kim, S.-S. (2013). The meaning of happiness as understood and articulated by young children. Journal of Early Childhood Education, 33(3), 377-400.

Kim, Y.-S., \& Shin, G.-H. (2016). Education research trends of 「Korea Academia-Industrial Cooperation Society」: 20062016. Journal of the Korea Academia-Industrial Cooperation Society, 17(9), 700-708. doi:10.5762/KAIS.2016.17.9.700

Kwark, H. K. (2011). A study of the relationship between happiness, self-identity and teacher's efficacy belief, teacher-young children interaction (Doctoral dissertation). Retrieved from http:// www.riss.kr/link?id=T12331325

Lee, E. J. (2010). A study on development of happiness scale for young children: Based on early childhood educational institution (Doctoral dissertation). Retrieved from http://www.riss.kr/ link?id=T11966481

Lee, H. O. (2014). Effects of mother's personality, marital relationship, and relationship with young children on happiness (Master's thesis). Retrieved from http://www.riss. $\mathrm{kr} / \mathrm{link}$ ?id=T13476278

Lee, K., Yoon, H., \& Byeon, S. (2016). An analysis of research trends in happiness studies in early childhood education. Journal of Early Childhood Education, 36(2), 497-514.

Lee, K.-M. (2009). Ideas for implementing pursuit of happiness education in early childhood education settings. Korean Journal of Children's Media, 8(1), 165-181.

Lee, S. B. (2015). Influence of the creative competency of early childhood education institutions, self-efficacy and teaching flow on happiness in early childhood teachers (Master's thesis). Retrieved from http://www.riss.kr/link?id=T13929545
Lee, Y. S. (2015). Exploring happiness of young children's fathers (Master's thesis). Retrieved from http://www.riss.kr/ link?id=T13697479

Lim, S.-R., Kim, J.-L., \& Jeon, B.-S. (2014). The development and validation of happiness measurement scale for early childhood teachers. Early Childhood Education Research \& Review, 18(1), 405-431.

Na, H.-S., \& Hwang, S.-Y. (2014). The relationship between the moral judgment and the happiness of young children. Early Childhood Education Research \& Review, 18(2), 269-288.

Nam, H. J. (2015). A study on the happiness of parents who have infantile children (Master's thesis). Retrieved from http:// www.riss.kr/link?id=T13688915

Nam, M. W., \& Oh, J. Y. (2016). The development of a happiness. sharing scale for preservice early childhood teachers. The Journal of Humanities and Social Science, 7(2), 91-115. doi:10.22143/HSS21.7.2.5

Oh, Y. J., Kim, H. J., \& Lee, J. S. (2015). Structural analysis of variables affecting right to be happy of children: Focus on age, gender, mother-child attachment, ego-resilience, and peer competence. Journal of Korean Council for Children \& Rights, 19(2), 187-209.

Park, J. (2015). The effect of nature walking activity on children's happiness (Master's thesis). Retrieved from http://www.riss. $\mathrm{kr} /$ link?id=T13673643

Park, S.-H., \& Park, E.-J. (2014). The relationship between early childhood teacher aptitude and sense of happiness. Early Childhood Education Research \& Review, 18(6), 165-190.

Ryu, M.-H. (2013). A study of the relations between young children's happiness and desire through investigating discourses on desire. Korea Journal of Child Care and Education 78, 5, 57-77.

Shin, J. H. (2016). Development of young children happiness program in relation with Nuri curriculum education and its effect (Doctoral dissertation). Retrieved from http://www.riss.kr/ link?id=T14006064

Shin, J.-H., \& Choi, H.-S. (2014). An analysis of trends in studies relating to early childhood happiness. Journal of Early Childhood Education, 34(1), 5-28.

Song, M.-S. (2014). An analysis of the research trend of theses about early childhood teacher's happiness. Korean Journal of Children's Media, 13(3), 149-169.

Won, J.-H. (2015). A structural analysis on early childhood educational teachers rewards happiness (Doctoral dissertation). Retrieved from http://www.riss.kr/link?id=T13837305

YI, H. S. (2015). The perception of happiness among the kindergarten teachers. The Journal of Korean Teacher Education, 32(3), 405-424. 
Received August 31, 2017

Youngsook Kim http://orcid.org/0000-0002-1915-0127

Sunhee Min https://orcid.org/0000-0002-6810-2471

Revision received October 22, 2017

Accepted January 31, 2018 